TẠP CHÍ KHOA HỌC ĐẠI HỌC TÂN TRÀO

ISSN: 2354 - 1431

http://tckh.daihoctantrao.edu.vn/

\title{
Đồ vải của các tộc người Đông Nam Á, sự tương đồng và khác biệt
}

\author{
Vi Văn $A n^{a}$ \\ ${ }^{a}$ Bảo tàng Dân tộc học Việt Nam
}

\section{Thông tin bài viết}

Ngày nhận bài:

$15 / 5 / 2018$

Ngày duyệt đăng:

$10 / 12 / 2018$

Tì khoá:

Đồ làm bằng tay; dẹt; thêu; vái lanh; Đông Nam Á; Batik; Ikat

\section{Tóm tắt}

Dệt ở các nước Đông Nam Á là nghề thủ công truyền thống có lịch sử lâu đời. Với sự phong phú, đa dạng về chủng loại và màu sắc, đạt đến trình độ tinh xảo, các sản phẩm dệt/đồ vải của họ đã góp phần làm nên bẳn sắc văn hóa tộc người ở từng quốc gia trong khu vực.

Đồ vải của các tộc người ở các quốc gia Đông Nam Á có nhiều điểm tương đồng, khác biệt góp phần làm nên cái thống nhất, cái đa dạng và được giới nghiên cứu đánh giá là một trong những khu vực có đồ vải dệt thủ công đẹp nổi tiếng thế giới. Tuy nhiên, cùng với quá trình hội nhập và toàn cầu hóa, đồ vải của các nước Đông Nam Á cũng đang đứng trước nhiều thách thức trước yêu cầu bảo tồn và phát triển.

\section{Giới thiệu chung}

Các nước Đông Nam Á vốn có các đặc điểm chung và nhiều yếu tố văn hóa tương đồng. Đó là: đa tộc người, đa ngữ hệ, đa tôn giáo, canh tác lúa nước và nương rẫy, tập quán ở nhà sàn, có nhiều nghề thủ công phát triển và vẫn duy trì những hình thức tín ngưỡng dân gian bản địa...

Một trong những nghề thủ công phổ biến và phát triển ở các quốc gia Đông Nam Á là nghề dệt. Đồ vải sản phẩm của nghề này vốn rất nổi tiếng bởi sự phong phú và đa dạng của chúng. Có thể khẳng định, dệt vải là nghề thủ công truyền thống có từ lâu đời, đóng vai trò hết sức quan trọng trong đời sống của cư dân ở khu vực này. Sản phẩm đồ vải là kết quả của sự lao động cần cù, sáng tạo của người dân qua nhiều thế hệ. Ngoài mục đích đáp ứng nhu cầu mặc, đồ vải còn là thứ quà tặng mang ý nghĩa đặc biệt trong các dịp cưới xin, tang ma, nghi lễ tín ngưỡng, tôn giáo. Đôi khi, đồ vải cũng còn được xem như một tiêu chí đánh giá sự giàu nghèo, vị thế và vai trò của chủ nhân trong xã hội. Đặc biệt, đồ vải đã trở thành sản phẩm hàng hóa trao đổi, mua bán giữa các tộc người, giữa các quốc gia với nhau. Vì thế, đồ vải cũng là một trong những yếu tố văn hóa tương đồng dễ nhận thấy nhất ở các tộc người trong các quốc

\section{gia Đông Nam Á.}

Tính đến cuối năm 2012, Bảo tàng DTHVN đã sưu tầm được 2.467 hiện vật văn hóa của 9 nước Đông Nam Á (kể cả Nam Trung Quốc), trong đó có trên 800 hiện vật đồ vải. Trong quá trình phân loại, cho dù theo tiêu chí chất liệu, chủng loại hay kỹ thuật dệt; chức năng hay giới tính... chúng tôi đều nhận thấy bên cạnh sự tương đồng (thể hiện ở chất liệu, công cụ, quy trình chế tác/sản xuất, kỹ thuật dệt...), sản phẩm đồ vải của các nước Đông Nam Á hiện có còn thể hiện những nét khác biệt nhất định. Đặc biệt, mỗi một tộc người ở mỗi vùng thuộc mỗi quốc gia trong khu vực thường là chủ nhân của một loại sản phẩm đồ vải nổi tiếng nào đó. Chẳng hạn, các đồ vải batik thường phổ biến ở các tộc người thuộc các quốc gia Đông Nam Á hải đảo: người Malay ở Malaysia, Singapore, trong đó vải batik ở vùng Java, Indonesia đạt đến độ tinh xảo và nổi tiếng hơn cả. Còn các sản phẩm đồ vải theo kỹ thuật ikat lại phổ biến ở các tộc người thuộc các quốc gia Đông Nam Á lục địa như Campuchia, Thái Lan, Lào, Myanma. Trong khi các đồ vải được tạo ra bằng sợ lanh phổ biến ở các cư dân vùng núi thì các sản phẩm đồ vải dệt bằng sợi bẹ chuối, bẹ lá dứa lại nổi tiếng ở Phipipines...

Bài viết dưới đây xin đề cập đôi nét về sự tương 
đồng và khác biệt trong đồ vải của các nước Đông Nam Á nêu trên.

\section{Nam Á \\ 2. Sự tương đồng đồ vải của các tộc người Đông}

\subsection{Sụ phong phú của nguyên liệu tạo ra các sản phẩm}

Theo đó, sợi bông và sợi tơ tằm là hai nguồn nguyên liệu khá phổ biến để dệt ra đồ vải. Bên cạnh đó, một số sản phẩm đồ vải còn được tạo ra bởi các nguồn nguyên liệu như vỏ cây, sợi lanh, hoặc sợi bẹ chuối, lá dứa (các tộc người ở Indonesia, Philippines...); có một số sản phẩm đồ vải còn gắn thêm các nguyên liệu như hạt cườm, gỗ, da; đính kim loại trang trí, tua đỏ... Đặc biệt, loại vải tinh xảo và xa xỉ nhất là vải kim tuyến, được dệt (hoặc thêu) bằng sợi tơ tằm kết hợp với sợi ngang phụ là sợi vàng hoặc sợi bạc mềm và mỏng. Nổi tiếng nhất là vải song ket của cư dân đảo Sumatra ở Indonesia và vải jongsarat ở Brunei. $\mathrm{Y}$ phục bằng vải kim tuyến sợi vàng, sợi bạc là loại sang trọng đặc biệt, trước kia chỉ dành riêng cho hoàng tộc và tầng lớp quyền quý như ở Thái Lan, Campuchia...

2.2. Việc tạo ra các sản phẩm đều gắn với một hệ thống công cụ truyền thống tương thích. Tuy nhiên, đối với mỗi loại nguyên liệu thường có cách chế biến và một loại công cụ đi kèm nhất định. Đối với sợi bông, quy trình sản xuất gồm: cán tách hạt, bật, lăn thành lọn, kéo thành sợi, tải lên guồng, luộc hồ nước gạo, nhuộm, tua vào suốt, dàn lên khung cửi và dệt thành vải. Hệ thống công cụ chế tác và sản xuất đồ vải từ nguyên liệu bông gồm: cán bông, bật bông, lọn bông, xa kéo sợi, guồng quay và se sợi, khung cửi... Đối với sợi tơ tằm, quy trình sản xuất gồm: kéo tơ, tải lên guồng thành lọn, nhuộm màu, dệt thành vải hoặc dùng làm chỉ thêu. Đối với sợi bẹ chuối và lá dứa, quy trình sản xuất gồm: tước thành sợi thô, ngâm cạo vỏ ngoài, xe thành sợi, nhuộm màu và dệt hoặc đan. Riêng với lanh, quy trình sản xuất gần tương tự như sợi bẹ chuối và bẹ lá dứa, nhưng có thêm công đoạn, dùng đá lăn, giã, nối sợi, se sợi rồi dệt. Đối với vỏ cây, các công đoạn thao tác gồm: rạch bóc vỏ, ngâm nước rồi cạo bỏ lớp vỏ cứng, đập dập cho mềm, giặt sạch, phơi khô rồi cắt khâu thành sản phẩm.

\subsection{Phổ biến là các kỹ thuật: Dệt trơn, batik, ikat, cài sợi ngang và thêu}

- Dệt trơn là kiểu dệt đơn giản nhất, chỉ gồm các thao tác đan cài các sợi dọc và ngang theo kiểu lóng mốt. Người ta thường áp dụng kỹ thuật này để dệt vải bông thô trắng, vải sọc, vải kẻ ô vuông hoặc dệt váy thường bằng sợi bông nhuộm chàm.

- Batik là thuật ngữ kết hợp của 2 từ Java "amba" (có nghiã là viết) và “titik" (nghĩa là chấm). Phương pháp này sử dụng sáp (hoặc các nguyên liệu khác có tính năng như sáp) nấu chảy để làm chất cản màu thuốc nhuộm ở những vùng nhất định của tấm vải trước khi nhuộm. Những hoa văn tinh xảo được gọi là batik tulis, được những người phụ nữ dùng tay vẽ bằng một công cụ có tên là canting (loại bút vẽ có chuôi bằng gỗ hoặc tre, đầu bút là một ống đồng, được gắn ngòi cong: 1,2 hoặc 3 ngòi). Kỹ thuật batik chủ yếu thường được áp dụng đối với loại vải sợi bông, vải lanh. Ngày nay, người ta áp dụng kỹ thuật này để trang trí trên gỗ và cả loại vải sản xuất bằng sợi tổng hợp.

Khi vẽ hoa văn, người ta cầm canting nhúng vào bát đựng sáp đã nóng chảy rồi miết lên toàn bộ bề mặt tấm vải, nhỏ sáp thành dòng liên tục, nhịp nhàng theo bước chân. Để batik có chất lượng, chất cản màu luôn được phết lên một mặt trước, sau đó mới đến mặt còn lại của tấm vải. Việc hoàn thành một tấm vải batik bao gồm một chuỗi những công đoạn bôi sáp đầu tiên và sau đó bôi sáp lên phần mới khác của tấm vải, xóa một số phần của lần bôi sáp đầu tiên và sau đó nhuộm lên một màu khác. Cách phối hợp để tấm vải có màu sắc theo ý muốn càng phức tạp, thì càng có nhiều công đoạn. Cuối cùng, tất cả sáp đều được tẩy sạch.

Nguồn gốc của kỹ thuật batik vẫn còn nhiều tranh cãi, bởi kỹ thuật này được sử dụng phổ biến ở nhiều nước như: Ấn Độ, Srilanka, Trung Quốc, Turkistan; các quốc gia tây Phi; các quốc gia Đông Nam Á, nhưng ở đảo Java của Indonesia, nghề thủ công này đã đạt đến đỉnh cao của sự tinh xảo. Không phải ở đâu, vải sử dụng sáp làm chất cản màu cũng đẹp, tỉ mỉ và tinh xảo như nơi này. Những trung tâm nổi tiếng về vải batik nằm ở miền trung Java ở hoàng thành Yogiakata và Solo cũng như ở các thị xã ven biển Cirebon, Pekalongan và Lasem ở phía bắc đảo Java. Đối với tầng lớp quý tộc, vải batik đóng vai trò quan trọng trong các nghi lễ long trọng, cũng như trong đời sống hằng ngày. Ở người Malay, batik thường được quấn cho trẻ sơ sinh, liệm thi hài cho người mới qua đời và phủ lên quan tài.

Ngoài sử dụng bút canting, các hoa văn in theo kỹ thuật batik còn được tạo ra bởi các bản khắc/bản dập kim loại gọi là cap. Khi vẽ hoa văn, người ta nhúng cáp vào sáp nóng chảy rồi đặt vào bề mặt của tấm vải. Thao tác này được thực hiện liên tục. Rõ ràng, việc sử dụng cap in sáp ong giúp vẽ mẫu hoa văn nhanh hơn, đều hơn, thường do đàn ông thực hiện. Do vậy, giá cả loại vải batik được sản xuất bằng loại bàn dập này cũng rẻ hơn loại vải batik dùng bút canting. 
- Ikat trong tiếng Malay là mengikat, có nghĩa là "buộc" hoặc "thắt". Còn trong tiếng Lào và tiếng Thái Lan, Ikat gọi là mặt mí, cũng có nghĩa là buộc thắt nút. Đó là quá trình những sợi vải được buộc và nhuộm trước khi dệt. Người ta căng sợi trên khung, sau đó được xếp thành các bó nhỏ và buộc chặt thành từng nút theo công thức định sẵn. Sau đó đem nhuộm màu, phần sợi bị buộc chặt sẽ không bị ngấm màu thuốc nhuộm. Sau khi nhuộm màu, người ta tháo dây những đoạn đã nhuộm lần đầu, để tiếp tục buộc thắt nút những khoảng sợi màu đã nhuộm rồi nhuộm màu khác. Quy trình này được lặp đi, lặp lại để sợi có nhiều màu theo ý muốn.

Kỹ thuật ikat chủ yếu được áp dụng đối với sợi bông, sợi tơ tằm (Indonesia, Myanmar, Thái Lan, Lào, Campuchia); sợi bẹ chuối, bẹ dứa (ở Philippines, Malaysia). Hiện nay, loại sợi tổng hợp đã được sử dụng trong kỹ thuật buộc cản màu bởi đặc tính chống thấm nước. Các sản phẩm vải Ikat được nhuộm theo 3 cách sau:

Ikat sợi dọc (những sợi chỉ dọc được buộc và nhuộm trước khi dàn sợi lên khung cửi). Ikat sợi dọc được coi là một trong những kỹ thuật sử dụng chất cản màu lâu đời nhất. Kỹ thuật này được áp dụng đối với sợi của các tấm vải trước khi dệt, giống như cách mà vải dệt được nhuộm cản màu sử dụng phương pháp buộc và nhuộm. Các họa tiết hoa văn của vải dệt được tạo ra bằng cách buộc thắt nút từng đoạn sợi dọc trên khung nhằm cản màu thuốc nhuộm, sau đó nhúng sợi vào trong bồn nhuộm. Ví dụ: nếu vải sợi gốc có màu trắng, bồn thuốc nhuộm có màu xanh da trời, thì phần được buộc sẽ tạo thành hoa văn màu trắng tương phản với nền xanh da trời. Bằng cách buộc thêm các đoạn khác của sợi dọc, khi bỏ một đoạn nào đó được buộc đầu tiên, sau đó nhúng nút đã buộc vào bồn nhuộm màu khác, hoa văn lúc này sẽ nổi lên 4 màu. Trong đó, màu đầu tiên là màu nguyên gốc không nhuộm của sợi vải dọc, màu thứ hai và thứ ba lần lượt là màu của hai bồn nhuộm và màu cuối cùng là màu sắc phối hợp của hai màu nhuộm đó. Khi quy trình nhuộm hoàn thành, người ta dàn sợi dọc lên khung cửi rồi dệt sợi ngang để tạo ra vải có hoa văn.

Kỹ thuật ikat sợi ngang là một quy trình phức tạp đòi hỏi nhiều vật liệu hơn ikat sợi dọc. Kỹ thuật này phổ biến ở những tín đồ Hồi giáo. Chất liệu được ưa chuộng nhất là sợi tơ tằm, nhưng cũng có thể áp dụng dễ dàng trên sợi bông hoặc tơ nhân tạo. Sợi ngang được dàn bằng tay trên một chiếc khung hình vuông hoặc hình chữ nhật, sau đó quấn chúng xung quanh một khung quay. Sợi được quấn dàn trên khung thành từng bó, sau đó dùng một loại lá hoặc dây nilon buộc thắt nút thành từng đoạn rồi nhuộm màu. Quy trình này cũng giống như các thao tác khi làm sợi dọc. Sợi có nhiều hay ít màu tùy thuộc vào việc buộc, nhuộm bao nhiêu lần. Sau khi nhuộm, sợi sẽ được dùng làm sợi ngang để dệt vào sợi dọc. Dệt đến đâu, hoa văn sẽ tự lộ ra đến đó.

Một phương pháp nhanh hơn để sản xuất vải ikat sợi ngang nhiều màu hiện nay được sử dụng ở Đông Nam Á bằng cách dùng màu nhuộm hóa học khác nhau phết lên những phần sợi sẽ được buộc lại sau đó. Có nghĩa là sợi vải chỉ cần nhúng vào một bồn nhuộm. Ở Indonesia, quy trình này được gọi là cetak. Ikat đôi (cả sợi dọc và sợi ngang đều được buộc, nhuộm trước khi dàn lên khung cửi để dệt) là kỹ thuật đòi hỏi người thợ dệt phải rất cẩn thận trong việc sắp xếp các mô-típ hoa văn và phải mất hàng tháng để buộc và nhuộm cả sợi dọc và sợi ngang, sau đó dệt thành tấm vải sao cho những họa tiết khớp với nhau mà không cảm thấy rời rạc. Kỹ thuật truyền thống này bắt nguồn từ Tây Ấn, sau đó được truyền vào Đông Nam Á và được duy trì ở Tenganan, phía đông Bali của Indonesia. Vải ikat đôi ở đây được gọi là geringsing. Ở Đông Nam Á, vải ikat đôi đã trở thành biểu tượng của hoàng tộc và được mô phỏng theo rất nhiều.

- Kỹ thuật dệt sợi dọc, sợi ngang bổ sung là cách lồng thêm một sợi dọc hoặc sợi ngang vào mảnh vải khi dệt. Vì sợi thêm vào này không quan trọng đối với kết cấu tấm vải, tức nó không phaỉ là sợi "nền" để giữ cho mảnh vải chắc chắn, nên nó được gọi là sợi dọc hoặc sợi ngang bổ sung. Khi dệt, người thợ chừa ra những đầu sợi để kết lại với sợi dọc và sợi ngang nền. Hoa văn bổ sung được giữ cố định bởi sợi bổ sung được dệt vào tấm vải đồng thời với sợi dọc và sợi ngang "nền". Sợi dọc hoặc sợi ngang bổ sung có thể phân biệt với nền vải bởi nó tạo ra hoa văn "nổi” của cả mặt trước và mặt sau tấm vải.

Sợi dọc phụ: Những sợi vải nền được dàn đều trên khung cửi với 2 dây go, sau đó những sợi dọc phụ dày hơn và sáng màu hơn được trải lên sợi vải nền. Người thợ dệt đặt một que tre giữa sợi nền và sợi phụ, gần mép vải để hai lớp sợi này không bị rối vào nhau. Mẫu hoa văn làm bằng dây và các thanh nẹp được sử dụng như bộ chỉ dẫn để sắp đặt hoa văn của sợi dọc phụ. Sau đó, rất nhiều thanh nẹp nhỏ bằng gỗ được đặt vào chỗ, lấy ra những sợi dọc phụ thích hợp để tạo thành hoa văn và những sợi ngang bắt đầu hiện ra. Trong quá trình dệt, những thanh nẹp được nhấc ra theo một trình tự để tạo thành hoa văn phụ trong dệt chéo. Ở những chỗ mà thanh nẹp được nhấc ra, những sợi dọc phụ sẽ xuất hiện trên bề mặt của tấm vải để tạo thành hoa văn; mặt khác nó sẽ xuất hiện ở mặt dưới như kiểu dệt nổi liên tục. Kỹ 
thuật dệt với những sợi dọc phụ thường tạo ra độ căng, nên cần phải liên tục điều chỉnh để giữ sợi nền và sợi phụ. Vải dệt sợi dọc phụ chỉ phổ biến ở Đông Indonesia, nhất là đảo Bali, Timor và Moluccas.

Sợi ngang phụ (liên tục) là những sợi ngang phụ bổ sung có thể được thêm vào tấm vải dệt để thêm họa tiết hoa văn trang trí cho một tấm vải trơn khác. Giống như những sợi dọc phụ, đây là những hoa văn trang trí và không phải là một phần thiết yếu của kết cấu tấm vải. Sợi ngang phụ thường có màu khác và dày hơn vải được dùng làm sợi ngang nền. Sợi ngang phụ liên tục là sợi ngang được nối từ mép này sang mép kia của tấm vải.

Để tạo hoa văn, những sợi ngang phụ cần được làm cho nổi lên hoặc biến mất bằng kỹ thuật dệt nổi qua những dây dọc ở điểm quan trọng. Kiểu dệt này gọi là dệt nổi ngang. Sợi ngang phụ khi không xuất hiện trên bề mặt của tấm vải, mà được nổi lên ở mặt kia và được buộc theo quy trình vào vải nền để duy trì tính toàn bộ của kết cấu.Với kết cấu dệt ngang phụ liên tục, những mẫu hoa văn trang trí sẽ xuất hiện với màu sẫm, tương phản với nền sáng hơn, trong khi ở mặt ngược lại, hoa văn sáng màu tương phản với nền tối màu. Vải sợi ngang phụ liên tục được dệt công phu và đẹp nhất có ở nhiều nơi trên thế giới, song có lẽ đẹp nhất là ở vùng Sầm Nưa, Bắc Lào như khăn quàng vai, dây lưng hay rèm màn.

Sợi ngang phụ (không liên tục) là hoa văn trang trí chỉ được dệt ở những chỗ lựa chọn, mà không dệt toàn bộ chiều rộng của khổ vải từ mép bên này sang mép bên kia. Cách hiệu quả nhất để sử dụng những sợi ngang phụ gián đoạn là dệt nổi hoặc dệt vào cùng một chỗ trên sợi ngang nền). Sợi không phải đặt từ mép tấm vải, mà từ điểm bắt đầu của hoa văn, trong khi những sợi ngang phụ liên tục thì được trải lên toàn bộ bề ngang của khổ vải. Để có hiệu quả khác nhau, kỹ thuật dệt chìm bao gồm một sợi ngang phụ được đặt vào với sợi nền, do đó hiệu quả tạo ra hoa văn tinh tế hơn, tấm vải chặt hơn và ít bị rách. Vải dệt theo kỹ thuật sợi ngang phụ không liên tục thường được dệt kết hợp với kiểu dệt sợi ngang phụ liên tục. Sợi ngang chìm được sử dụng với các mô-típ hoa văn hình động vật, thực vật với đặc trưng cách điệu và mô phỏng.

- Kỹ thuật thêu có 2 cách: thêu mặt phải hoặc thêu mặt trái của tấm vải. Nếu như hoa văn tạo từ kỹ thuật dệt thường chỉ thể hiện sự mô phỏng tượng trưng thì hoa văn tạo ra từ kỹ thuật thêu chẳng những phong phú, đa dạng về hình dáng, màu sắc, mà còn có thể đáp ứng được cả hai phong cách thể hiện: mô phỏng, cách điệu và tả thực rõ nét. Rõ ràng, trong kỹ thuật dệt với các thao tác chính là bắt go, đan cài và luồn sợi theo công thức nhất định, người ta không thể tạo được những đường cong tự nhiên, mềm mại hay những nếp uốn theo ý muốn. Trong khi đó, kỹ thuật thêu có thể khắc phục được hạn chế này và còn có khả năng sáng tạo trong quá trình thể hiện đồ án hoa văn.

2.4. Phong phú về các mô - típ hoa văn trang trí cũng như màu sắc. Theo đó, các mô- típ hoa trang trí phổ biến trên các sản phẩm đồ vải thường là hoa văn hình học, hình động vật (rồng, người, voi, ngựa, hươu, tê giác, ba ba...); thực vật (hoa lá, cỏ cây...); hình học (hình vuông, hình chữ nhật, hình quả trám...) và các mô típ khác như hình mặt trời/hình ngôi sao tám cánh hay các biểu tượng tôn giáo (hình chùa tháp, thánh đường)... theo phong cách tượng trưng, cách điệu hay tả thực; với các gam màu đỏ, vàng, da cam, đen, trắng... đậm hay nhạt, tùy theo tập quán và sở thích của mỗi tộc người ở mỗi quốc gia trong khu vực. Về ý nghĩa, các mô típ hoa văn hình động vật hay hình thực vật thể hiện sự cách điệu và hình tượng hóa động, thực vật vốn gần gũi trong cuộc sống hằng ngày. Ở một khía cạnh nào đó, các mô típ hoa văn này còn thể hiện sắc thái văn hóa của cư dân nông nghiệp trồng trọt lúa nước (biểu tượng hình rồng - con vật huyền thoại tượng trưng cho sức mạnh), yếu tố tín ngưỡng, yếu tố văn hóa biển (hình thuyền, sóng nước), hay yếu tố văn hóa Hồi giáo (hình tháp) và Phật giáo (hình chữ Phạn).

2.5. Phong phú về chủng loại sản phẩm. Theo đó, có thể kể đến các sản phẩm đồ vải phổ biến như váy, áo, quần, khố, xà rông; tấm choàng, khăn đội đầu (nam, nữ), địu trẻ em, mặt chăn, rèm và tấm trang trí; xà cạp, gối, đệm, ga trải giường, túi đeo, tấm chéo...

Căn cứ vào nguyên liệu dệt, chúng ta có thể thấy sản phẩm đồ vải từ nguyên liệu bông thường có: vải mộc trắng (dùng may quần áo tang, liệm thi hài người chết), vải đen nhuộm chàm hoặc nhuộm phẩm màu, dùng để cắt may áo, váy, quần, khố, màn... Sản phẩm đồ vải từ nguyên liệu tơ tằm gồm có: váy, khăn, mặt chăn, tấm trang trí, rèm buồng, địu trẻ em... Còn sản phẩm đồ vải từ nguyên liệu sợi lá dứa, bẹ chuối, sợi lanh hay vỏ cây thường là váy, áo, khố, mặt chăn...

\section{Nét khác biệt đồ vải của các tộc người Đông Nam Á}

\subsection{Khác nhau trong sủ̉ dụng nguyên liệu}

Như trên đã đề cập, mặc dù cùng phổ biến trong việc sử dụng nguyên liệu như sợi bông, tơ tằm hay kể cả sợi kim loại (vàng, bạc, kim tuyến) để tạo ra sản phẩm đồ vải, song ở mỗi quốc gia (thậm chí mỗi dân 
tộc) Đông Nam Á lại có sự chênh lệch/nét khác biệt trong việc sử dụng các nguyên liệu nêu trên để sản xuất ra các loại đồ vải nói chung. Cụ thể là, tại các quốc gia Đông Nam Á lục địa, ta thấy việc sử dụng nguyên liệu bông, tơ tằm, sợi lanh hay vỏ cây thường phổ biến và chiếm ưu thế hơn. Trước kia, những quốc gia này tồn tại chế độ quân chủ (Thái Lan, Campuchia, Lào, Myanmar và cả Việt Nam), nên việc sử dụng nguyên liệu sợi vàng, sợi bạc kết hợp với sợi tơ tằm trong việc tạo ra các sản phẩm dệt, nhất là $\mathrm{y}$ phục của nhà vua cũng như y phục của các thành viên hoàng gia/nhà giàu có cũng khá phổ biến. Trong khi đó, tại các quốc gia Đông Nam Á hải đảo (Indonesia, Malaysia, Philippines, Brunei... vốn theo đạo Hồi), ta lại thấy việc sử dụng các nguyên liệu sợi bông, sợi lá dứa, bẹ chuối chiếm ưu thế hơn. Bên cạnh đó, việc sử dụng các nguyên liệu sợi kim loại cũng chỉ phổ biến ở một số quốc gia như Brunei, Indonesia, Malaysia trước đây. Tuy vẫn có, song các nguyên liệu như tơ tằm, vỏ cây hay sợi lanh dường như không phổ biến là bao.

\subsection{Khác nhau về kỹ thuật dệt, thêu}

Trong hơn 800 hiện vật đồ vải hiện có tại Bảo tàng DTHVN, khi phân loại, chúng tôi nhận thấy dường như các quốc gia Đông Nam Á hải đảo có thế mạnh về sử dụng thuật batik để tạo hoa văn hơn các quốc gia Đông Nam Á lục địa. Không nghi ngờ gì nữa, khi nói đến kỹ thuật batik của Đông Nam Á, người ta sẽ nghĩ ngay tới các sản phẩm đồ vải batik nổi tiếng của người Giava, người Malay ở Indonesia, Malaysia và cả ở Singapore nữa. Cũng chính vì thế, các dụng cụ dùng để thực hành kỹ thuật batik như bút ngòi (canting) với các kích cỡ khác nhau hay các loại bàn dập bằng đồng với nhiều mẫu mã hoa văn (cap) hiện nay vẫn được sử dụng phổ biến ở các quốc gia hải đảo nêu trên. Trong khi đó, kỹ thuật này ở các quốc gia Đông Nam Á lục địa hầu như chỉ được lưu giữ ít ỏi ở một số tộc người như Hmông, Dao ở Việt Nam, Lào hay Choang ở Nam Trung Quốc. Bên cạnh đó, tại các quốc gia Đông Nam Á hải đảo (Indonesia, Philippines, Malaysia) còn phổ biến và nổi tiếng sử dụng kỹ thuật ikat, áp dụng đối với sợi bông, sợi tơ tằm, sợi bẹ chuối, bẹ dứa. Trong khi kỹ thuật này chỉ phổ biến ở một số quốc gia Đông Nam Á lục địa, trong đó nổi trội hơn cả là người Khơ-me ở Campuchia. Kỹ thuật dệt sợi dọc, sợi ngang bổ sung (liên tục hoặc không liên tục) thường phổ biến ở các tộc người theo đạo Hồi thuộc các quốc gia Đông Nam Á hải đảo và người Lào, Phu Thay ở Bắc Lào và Đông Bắc Thái Lan, Bắc Myanmar. So với các quốc gia Đông Nam Á hải đảo, kỹ thuật thêu của các tộc người ở các quốc gia Đông Nam Á lục địa, bào gồm cả Nam Trung Quốc có phần phổ biến và nổi tiếng hơn.

Cũng cần nói thêm rằng, giữa các quốc gia Đông Nam Á hải đảo và lục địa cũng có sự khác nhau về tập quán/ưu thế sử dụng các kiểu khung dệt. Theo đó, các tộc người ở các quốc gia Đông Nam Á lục địa phổ biến sử dụng khung dệt hình vuông, hình chữ nhật hay kiểu khung dệt Môn-Khơme; với khổ vải dệt thường hẹp. Trái lại, các tộc người ở các quốc gia Đông Nam Á hải đảo lại phổ biến kiểu khung dệt đứng, dùng tay đan như kiểu dệt thảm hoặc khung đặt chếch, dùng go; với khổ vải dệt thường rộng.

\subsection{Khác nhau về các môtíp hoa văn trên đồ vải}

Các tộc người Đông Nam Á hải đảo thiên về yếu tố nước: hình học, hoa lá, hình sóng nước, hình người, hình rồng và hình tháp (yếu tố Hồi giáo); còn các tộc người Đông Nam Á lục địa lại thiên về hình rồng, hình động vật (cách điệu), hình học và hình chữ Phạn (yếu tố Phật giáo).Về gam màu, đồ vải các nước Đông Nam Á hải đảo thiên về màu sẫm, nền đen; còn đồ vải các nước Đông Nam Á lục địa lại thiên về màu đỏ, sặc sỡ; màu vàng, nền đen.

\section{Nhận xét}

Từ những cứ liệu đã trình bày trên đây, chúng ta thấy, nghề dệt ở các nước Đông Nam Á là nghề thủ công truyền thống có lịch sử lâu đời. Với sự phong phú, đa dạng về chủng loại và màu sắc, đạt đến trình độ tinh xảo, các sản phẩm dệt/đồ vải của họ đã góp phần làm nên bẳn sắc văn hóa tộc người ở từng quốc gia trong khu vực.

Đồ vải của các tộc người ở các quốc gia Đông Nam Á có nhiều điểm tương đồng: Sự phong phú của nguyên liệu tạo ra các sản phẩm; Việc tạo ra các sản phẩm đều gắn với một hệ thống công cụ truyền thống; Phổ biến là các kỹ thuật: Dệt trơn, batik, ikat, cài sợi ngang và thêu; Phong phú về các mô - típ hoa văn trang trí và màu sắc; Phong phú về chủng loại sản phẩm. Sự khác biệt thể hiện ở: Cách thức sử dụng nguyên liệu; Một số khâu kỹ thuật dệt thêu cụ thể; Một số mô típ hoa văn cụ thể. Sự tương đồng và khác biệt trong đồ vải cũng chính là biểu hiện của tính thống nhất và đa dạng về văn hóa của khu vực Đông Nam Á, vốn cùng dựa trên cơ tầng văn hóa chung. Nói cách khác, những đặc trưng về đồ vải của mỗi nước góp phần làm nên cái thống nhất, còn những nét/sắc thái riêng về đồ vải của mỗi nước thì góp phần làm nên cái đa dạng của Đông Nam Á.

Hiện nay, ngoài phục vụ nhu cầu trong mỗi nước, nhiều sản phẩm đồ vải batik và ikat... đẹp nổi tiếng với nhiều mẫu mã mới của khu vực Đông Nam Á đã có mặt tại nhiều nước trên thế giới, được khách hàng ưa 
chuộng. Đây cũng là những lý do khiến cho Đông Nam Á được giới nghiên cứu đánh giá là một trong những khu vực có đồ vải dệt thủ công đẹp nổi tiếng thế giới. Tuy nhiên, cùng với quá trình hội nhập và toàn cầu hóa, đồ vải của các nước Đông Nam Á cũng đang đứng trước nhiều thách thức trước yêu cầu bảo tồn và phát triển.

Nhận thức và hiểu biết sâu sắc và kỹ lưỡng về tương đồng và khác biệt trong đồ vải sẽ rất hữu ích trong việc thể hiện chủ đề về trang phục và đồ vải trong trưng bày thường xuyên văn hóa các nước Đông Nam Á. Bên cạnh đó, ngoài góp phần thiết thực cho việc nghiên cứu, tìm hiểu về đồ vải nói chung, hiểu biết về vấn đề này cũng sẽ giúp ích cho các trưng bày chuyên đề về văn hóa Đông Nam Á nói riêng trong tương lai mà Bảo tàng DTHVN sẽ hướng tới.

\section{TÀI LIÊU THAM KHẢO}

1. Maxwell, Robyn, Textiles of South-East Asia: Tradition, Trade and Transformatin. Melbourn,
Australia National Gallery, 1990.

2. Leedom Lefferts, Textiles and Tai experience in Southeast Asia. Washington DC,1992.

3. Michael. C.Howard, Kim Be. Howard. Textiles of Southeast Asia: An Anotated \& lllustrated Bibliography.BangKok White Lotus Press, 1994.

4. Fiona Kerlogue, The book of Batik. Archipelago Press, Singapore, 2004.

5. Nhiều tác giả, Đồ vải của người Thái ở tiểu vùng sông Mê Công: tiếp nối và biến đổi (Việt, Anh).Bảo tàng Dân tộc học Việt Nam, H, 2006.

6. Michael. C.Howard, Bark-cloth in Southeast Asia (editor). Bangkok: White Lotus Press, 2006.

7. Michael.C.Howard, A World Between the Warps: Southeast Asia's Supplementary Warp Textiles. Bangkok: White Lotus Press, 2008.

8. Nhiều tác giả, Catalogue Văn hóa Đông Nam Á (Việt, Anh, Pháp). Bảo tàng Dân tộc học Việt Nam, H, 2010.

\section{Fabric products of Southeast Asian nations are of similarities and differences}

Vi Van An

\section{Article info}

Recieved:

15/5/2018

Accepted:

$10 / 12 / 2018$

Keywords:

Handmad; weave, embroider; linen, Southeast Asia; Batik;Ikat.

\begin{abstract}
Weaving in Southeast Asian countries has been a traditional handicraft with a long history. With the plentiful and diverse types and colors, reaching the level of sophistication, their textile / fabric products have contributed to the national identity of each country in the region.
\end{abstract}

Fabric products of ethnic groups in Southeast Asian countries have many similarities, difference. The similarities and differences in fabric products are also an indication of the cultural unity and diversity of Southeast Asia, which is basically based on a common cultural background. In other words, features of fabric products in each country contribute to the unity, while individual features / nuances of each country contribute to the diversity of Southeast Asia.

Currently, in addition to meeting the demands of each country, many beautiful batik and ikat products which are well-known with a variety of new models of Southeast Asia are now present in many countries around the world and favored by customers. This is also the reason why Southeast Asia has been evaluated as one of the areas possessing beautiful handmade fabric product which are worldwide famous by researchers. However, moving along with the process of integration and globalization, fabric products of Southeast Asian countries are also facing many challenges of conservation and development. 